\title{
Utilization of Youth Reproductive Health Services and Associated Factors among High School Students in Bahir Dar, Amhara Regional State, Ethiopia
}

\author{
Meskerem Abebe1, Worku Awoke ${ }^{2 *}$ \\ ${ }^{1}$ GAMBY Colleges of Medicine and Health Sciences, Bahir Dar, Ethiopia \\ ${ }^{2}$ College of Medicine and Health Sciences, Bahir Dar University, Bahir Dar, Ethiopia \\ Email: Workuawo@yahoo.com
}

Received 25 February 2014; revised 25 March 2014; accepted 1 April 2014

Copyright @ 2014 by authors and Scientific Research Publishing Inc.

This work is licensed under the Creative Commons Attribution International License (CC BY). http://creativecommons.org/licenses/by/4.0/

(c) (i) Open Access

\section{Abstract}

Introduction: Young people in Ethiopia face greater reproductive health risks than adults. Despite efforts that were made on youth to utilize reproductive health service, studies show that there is little information about the extent to which youth utilize available health services. For the proper planning of appropriate health services for youth, it is crucial to have knowledge on the pattern of their use and its associated factors. So this study was conducted from June to September 2013 to assess utilization of youth reproductive health and its associated factors among high school students in Bahir Dar town, Amhara region, Ethiopia, 2013. Methods: Institutional based cross-sectional study was conducted among High school student from June to September 2013. Multistage sampling technique was used to select the total of 818 study participants. Data were collected by means of a pretested standardized questionnaire; analysis was carried out using SPSS version 16. Crude and adjusted odds ratio with $\mathbf{9 5 \%}$ confidence interval was calculated using binary logistic regression; p-value less than 0.05 was considered as statistically significant. Results: The study indicated that among 818 students, $480(58.7 \%)$ were females. The data indicates that, $32 \%$ of youth utilized youth reproductive health service. Barriers in utilizing reproductive health services, for $31 \%$ of the students were due to inconvenience hours and $28.5 \%$ were due to fear of being seen by parents or people whom they know. Among socio-demographic predictors, age and reproductive health problems showed a significant association with utilization of youth reproductive health services. Students with age 20 - 24 were 2.31 times more likely to utilize reproductive health ser-

\footnotetext{
${ }^{*}$ Corresponding author.
}

How to cite this paper: Abebe, M. and Awoke, W. (2014) Utilization of Youth Reproductive Health Services and Associated Factors among High School Students in Bahir Dar, Amhara Regional State, Ethiopia. Open Journal of Epidemiology, 4, 69-75. http://dx.doi.org/10.4236/ojepi.2014.42012 
vice than age15 -19 (AOR $=2.31$, CI 95\% $(1.01,5.28)$ ). Similarly, students who had reproductive health problems were 1.54 times more likely to utilize reproductive health services than students who had no reproductive illness. Conclusions: The majority of youth were not utilizing reproductive health services. Age and reproductive health problems showed a significant association with utilization of youth reproductive health services.

\section{Keywords}

\section{Youth Reproductive Health, Utilization, Ethiopia}

\section{Introduction}

According to World Health Organization, youth are defined as persons between 15 and 24 years of age and are characterized by significant physiological, psychological and social changes that place their life at high risk and making up about $20 \%$ of the world's population, of whom $85 \%$ live in developing countries [1].

As reports show that sexual activity, early pregnancies and sexually transmitted infections (STIs) including human immune deficiency virus (HIV) infection rates are increasing at unprecedented rates among adolescents, adolescent and youth reproductive health becomes a concern [2] [3].

Considering these problems, many countries have started giving a due attention to the problems of youth and adolescents after the declaration of international year of youth by United Nation (UN) in 1985 and the Cairo 1994 International Conference for Population and Development (ICPD). Among the strategies being performed to solve the problems of youth, establishing youth friendly services is the major one in addressing the reproductive and sexual health need of youth [4].

Ethiopian government adopts youth friendly services and additionally, Health Extension Program (HEP) has institutionalized to strengthen the delivery of preventive, promotive and basic health care in the rural area to reach adolescents and youth at the community level [5]. Not only the government of Ethiopia but also other non-governmental organizations support this program.

Despite these efforts, there is little information about the extent to which youth utilize available health services in Ethiopia as most studies that examined the use of health services had primarily focused on adults [6].

A national study conducted by $\mathrm{MOH}$ on selected urban areas of Ethiopia (Oromia, Amahara, Southern people and Tigray) showed that youth couldn't properly utilize the available health service [7]. For the proper planning of appropriate health services for youth, it is crucial to have knowledge of the pattern of their use and its associated factors.

So, this study was conducted to assess utilization of youth reproductive health and its associated factors among high school students in Bahir Dar town Amhara region, Ethiopia, 2013.

\section{Methods}

\subsection{Study Design}

Institutional based Cross-sectional study design was carried out in Bahar Dar town, Amhara Regional State from June to September, 2013.

\subsection{Study Area}

Bahir Dar town administrative is located in the North Western part of Ethiopia. In the town, 15 - 24 age accounts 78,930. There are 2 general hospitals and 35 clinics which are private owned with different categories in the town. There are 8 high schools of theses 4 are governmental high schools and there are a total of 11,965 students in these schools [8].

\subsection{Sampling Method and Sample Size Determination}

The sample size was determined by using single population proportion formula by considering the following assumption: Prevalence of utilization of were $40 \%$ as a study done in Adiss Ababa among high school students 
[9] ( $\mathrm{p}=40 \%$ ), level of significance $(\alpha=5 \%)$, 5\% marginal error, designing effect of 2 and by adding $10 \%$ of non response rate which gave the final sample size to be 818 . Then, Simple random sampling technique was used to select the study subjects.

\subsection{Data Collection Instruments and Procedure}

Data was collected using self administered pretested standardized questioners.

The data collectors and supervisors were trained for two days a day before the pretest and a day after the pretest. After pretest discussion was carried out with facilitators and some corrections and changes were made on the questionnaires by principal investigator .Multistage sampling technique was used in order to select a representative sample of students. Four out of 8 government and private schools were selected using simple random technique. The total sample was allocated to the selected schools proportionate to their student population size. Grade $9^{\text {th }}$ and $11^{\text {th }}$ students were selected from the school as others have finalized their national examination and were not available during data collection time. From each grade, sections were selected randomly and finally the study subjects were selected by using lottery method using their attendance lists.

On the day of data collection, randomly selected students were told to remain in their classes. All students gave their consent to participate. Remarks were given to study subjects to ask questions if any and not to jump any question unless they are not in need to respond the specific question.

\subsection{Data Analysis}

Analysis was done using SPSS version 16 soft ware. Univariate analyses were done using frequency, percentage, tables and charts. Associations between dependent and independent variables were assessed using logistic regression. Multivariate analysis was done using backward stepwise logistic regression to assess individual effect of variables on services utilizations. Crude and adjusted odds ratio with 95\% confidence interval was calculated using binary logistic regression; $\mathrm{p}$-value less than 0.05 was considered as statistically significant.

\subsection{Ethical Considerations}

Ethical clearance was sought from GAMBY College of Medical Sciences. Permission was obtained from Amhara Regional Health Bureau research and technology transfer core process Bahir Dar town Education office. Moreover; all selected participants were communicated about the objective of study. Participants were also informed their full right to withdraw or refuse to participate in the study. Data were collected after getting informed consent from the selected youth.

\section{Results}

\subsection{Socio-Demographic Characteristics of the Respondents}

A total of 818 students were participated in the study: Of these 480(58.7\%) were females and 338 (41.3\%) were males. The response rate was hundred percent. Among the respondents, 575(70.3\%) and 242(29.7\%) were attending grade 9 and 11 respectively. Seven hundred ninety seven (97.7\%) were Amhara by ethnicity. The majority, 90.6\%, were Orthodox Christian followers. From the total respondents, 571(71\%) were living with their both parents, the rest were either with mother or father only, or with relatives and other (Table 1).

Two hundred sixty three (32.2\%) of the respondents utilized reproductive health services. The major factors in utilizing reproductive health by youths were inconvenience service hour (31.8\%), feel fear to be seen by parents or other adults (28.5\%) and too long waiting hours (28.4\%). Second category of barriers were consultation hour is too short (25.4\%) providers are judgemental and unfriendly (23.6\%) feel embracement at seeking or going to RH services (21.6\%) (Table 2).

\subsection{Accessibility and Affordability of Health Facility as Perceived by High School Students}

Participant who had no access to health service in nearby were $13.6 \%$. Similarly, $15.5 \%$ of the study participants couldn't afford the cost for payment of the health services (Figure 1). 
Table 1. Socio-demographic characteristics of high school students, Bahir Dar town, North West Ethiopia, June 2013 ( $\mathrm{N}=818)$.

\begin{tabular}{|cc|}
\hline Socio demographic Variables & N (\%) \\
\hline Sex & \\
Female & $480(58.7 \%)$ \\
Male & $338(41.3 \%)$ \\
Age & \\
$15-19$ & $793(96.9 \%)$ \\
$20-24$ & $25(3.1 \%)$ \\
Grade & \\
9 & $575(70 \%)$ \\
11 & $243(29.7 \%)$
\end{tabular}

\section{Marital status}

$\begin{array}{cc}\text { Single } & 778(95.1 \%) \\ \text { Married } & 32(3.9 \%) \\ \text { Separated } & 7(0.9 \%) \\ \text { Widowed } & 1(0.1 \%)\end{array}$

Religion

Orthodox 741(90.6\%)

Muslim 56(6.8\%)

Protestant 17(2.1\%)

Catholic 2(0.2\%)

Others $2(0.2 \%)$

Ethnicity

$\begin{array}{cc}\text { Amahara } & 797(97.4 \%) \\ \text { Tigre } & 10(1.2 \%) \\ \text { Oromo } & 6(0.7 \%) \\ \text { Agew } & 3(0.4 \%) \\ \text { Others } & 2(0.2 \%)\end{array}$

Table 2. Health facility and provider factors on youth reproductive health service utilization among high school students, Bahir Dar town, June 2013.

\begin{tabular}{cc}
\hline Variables & (\%) \\
\hline Youth reproductive health services hours are inconvenience & 31.8 \\
Fear being seen by parents or others when you visiting RH services. & 28.5 \\
Reproductive health services waiting hours are too long. & 28.4 \\
Service providers are judgmental and unfriendly. & 23.6 \\
Feel embracement at seeking or going to RH services. & 21.6 \\
\hline
\end{tabular}




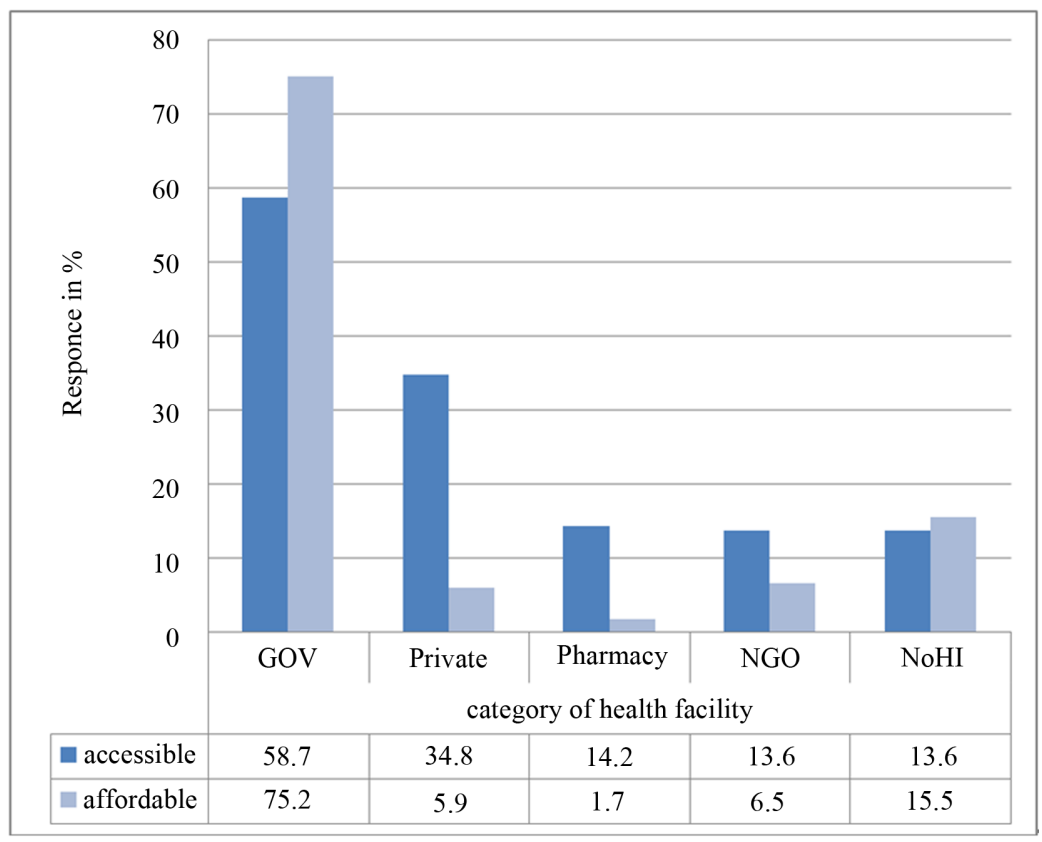

Figure 1. Accessibility and affordability of reproductive health services as perceived by high school students, Bahir Dar town, June 2013.

\subsection{Factors Associated with Utilization of Youth Reproductive Health Service and Its Associated Factors among High School Students in Bahir Dar Town, 2013}

The effects of different independent variables were tested for utilization of youth reproductive health using logistic regression analysis. Age of youth and exposing to RH problems were significantly associated with utilization youth reproductive health service. Youth who were in the age group of 20 - 24 years were about 2.34 times more likely to use RH services than whose age ranges from 15 - 19 years (AOR $=2.34,95 \% C I(1.02,5.38)$ ). Youth with RH problems were 1.59 times more likely to use RH service than those with no RH problems (AOR $=1.53,95 \% \mathrm{CI}(1.10,2.13))$ (Table 3$)$.

\section{Discussion and Concussions}

Utilization of youth reproductive health service among high school students in Bahir Dar town was found to be $32.2 \%$, elicited by asking past one year use of RH services from the date of data collection and this was lower as compared to study conducted in Adiss Ababa 40\% [9], and community study undertaken in Jimma 41\% [10], Harar 36\% [11] and greater than study conducted Machakal district 21.5\%, Northwest Ethiopia [12]. The findings of this study also indicated that youth used various health facilities similar to those previous studies conducted in Jimma [10].

This study also showed that a small proportion (3\%) of the participants used traditional health service and it was in line with Jimma [10] and Machakal study 3.14\%, 3.1\% respectively [12].

In this study, the presence of RH illnesses was associated with the utilization RH service. Participants who had RH problems were 1.54 times more likely to utilize RH services than those not ill (AOR $=1.54,95 \% \mathrm{CI}$ $(1.11,5.14))$. The factors affecting utilization of health services are the health status of the individual [13] and the type of illness [6]. This might show health seeking behavior of the respondents.

Age of respondents is found to be associated with the utilization of youth reproductive health service. Youth within age groups of 20 to 24 years were 2.31 times more likely to use RH services than youth of age 15 to 19 years $(\mathrm{AOR}=2.31,95 \% \mathrm{CI}(1.01,5.28)$ ). This finding is in agreement with the study conducted in Jimma [10].

In this study, $88.1 \%$ respondents were accessed at least for one health facility but the utilization was low. Despite better access, the utilization of health services was low. Study participants claimed that: reproductive health service working hours were inconvenient (31.8\%); waiting hours were too long (28.4\%); service providers were judgmental and unfriendly (23.6\%) and on their attitude side fear of being seen by parents or people 
Table 3. Factors associated with utilization of youth reproductive health services among high school students, Bahir Dar town, 2013.

\begin{tabular}{|c|c|c|c|c|}
\hline \multirow{2}{*}{ Variables } & \multicolumn{2}{|c|}{ Utilization of use reproductive health } & \multirow{2}{*}{ COR 95\%CI } & \multirow{2}{*}{ AOR 95\%CI } \\
\hline & Yes & No & & \\
\hline \multicolumn{5}{|l|}{ Age } \\
\hline $15-19$ & 249 & 554 & 1 & 1 \\
\hline $20-20$ & 14 & 11 & $2.78(1.24,6.21)$ & 2.31(1.01,5.28) \\
\hline \multicolumn{5}{|l|}{ RH illness } \\
\hline No & 175 & 422 & 1 & 1 \\
\hline Yes & 88 & 133 & $1.59(1.15,2.20)$ & $1.54(1.11,2.14)$ \\
\hline \multicolumn{5}{|l|}{ Affordability } \\
\hline Can't afford & 34 & 92 & 1 & 1 \\
\hline Can afford & 229 & 463 & $1.33(0.87,2.04)$ & $0.93(0.55,1.58)$ \\
\hline
\end{tabular}

who know them (28.5\%), they deter to utilize reproductive health service. This indicates that geographic accessibility only does not imply the utilization of health services. This is also evidenced by other studies carried out in Harar [14].

\section{Acknowledgements}

We would like to thank GAMBY College of Medical sciences, Amhara Regional Health Bureau research and technology transfer core process, and Bahir Dar town Education and Health office. We are also grateful for the cooperation of the study participants, data collectors and supervisors.

\section{References}

[1] WHO (1999) Programming for Adolescent Health and Development Report of WHO/UNFPA/UNICEF Study Group on Programming for Adolescents Health. WHO, Geneva.

[2] Malleshappa1, K., Shivaram, K. and Nandini, C. (2011) Knowledge and Attitude about Reproductive Health among Rural Adolescent Girls in Kuppam Mandal: An Intervention Study. Biomedical Research, 22, 305-310.

[3] Hughes, J. and McCauley, A.P. (1998) Improving the Fit: Adolescents’ Needs and Future Programs for Sexual and Reproductive Health in Developing Countries. Studies in Family Planning, 29, 233-245.

[4] UNFPA (1998) Sexual and Reproductive Health of Adolescents: A Review of UNFPA Assistance. Technical Report No. 48.

[5] Ethiopia Federal Ministry of Health (2006) National Adolescent and Youth Reproductive Health Strategy. http://phe-ethiopia.org/resadmin/index.php?news=60

[6] Fantahun, M. and Degu, G. (2003) Health Service Utilization in Amhara Region of Ethiopia. Ethiopian Journal of Health Development, 17, 141-147.

[7] Ministry of Health (2006) Reproductive Health Needs and Youth Friendly Health Service Assessment in Selected Urban Areas of the Oromia, Amhara, Southern Nations and People and Tigray Regional States.

[8] (2012) Bahir Dar City Administration Education Bureau. 2012 Annual Report (Unpublished).

[9] Berhane, F., Berhane, Y. and Fantahun, M. (2005) Adolescents' Health Service Utilization Pattern and Preferences: Consultation for Reproductive Health Problems and Mental Stress Are Less Likely. Ethiopian Journal of Health Development, 19, 29-36.

[10] Tegegn, A. and Gelaw, Y. (2009) Adolscent Reproductive Health Service Accessibility and Utilization in Jimma City Ethiopia. Ethiopian Journal of Health Development, 19, 91-100.

[11] Motuma, A. (2012) Youth-friendly Health Services Utilization and Factors in Harar, Ethiopia. Harar Bulletin of Health Sciences, 4, 15-21.

[12] Abajobir, A. and Seme, A. (2013) Reproductive Health Knowledge and Services Utilization among Rural Adolescents 
in Machakal District, Northwest Ethiopia. Asian Journal of Pharmacy, 1, 27-36.

[13] Andersen, R.M. (1995) Revisiting the Behavioral Model and Access to Medical Care: Does It Matter? Journal of Health and Social Behavior, 36, 1-10. http://dx.doi.org/10.2307/2137284

[14] Worku, S. and Fantahun, M. (2006) Unintended Pregnancy and Induced Abortion in a Town with Accessible Family Planning Services: The Case of Harar in Eastern Ethiopia. Ethiopian Journal of Health Development, 20, 79-83. 